\title{
Arts and Humanities and the others: Why can't we measure arts and humanities
}

\author{
Zehra Taşkın ${ }^{1,2, *}$, and Güleda Doğan ${ }^{2}$ \\ ${ }^{1}$ Adam Mickiewicz University, Scholarly Communication Research Group, Poznań, Poland \\ ${ }^{2}$ Hacettepe University, Department of Information Management, Ankara, Turkey
}

\begin{abstract}
The use of numbers (publications and citations) to evaluate research/er performances are widespread since ease of use. However, disciplinary differences must be considered to evaluate research/ers accurately without misjudgments in tenures and incentives. The most different filed from others in terms of publications and citation patterns is Arts \& Humanities. The main aim of this study is to reveal the main differences between Arts \& Humanities and the other fields by considering publications, citations, and collaboration. For this aim, the main statistics for 59,728,700 papers published between 1980-2018 are gathered from InCites in terms of the $251 \mathrm{Web}$ of Science subject categories. The data confirmed that Arts \& Humanities is considerably different from other fields. We showed the degree of these differences using statistical measures. The huge difference found out that underline the indispensability for evaluating Arts $\&$ Humanities separately from the others.
\end{abstract}

\section{Introduction}

For the last couple of decades, policy-makers and managers try to find solutions for measuring research performance. After the foundation of the Institute for Scientific Information (ISI) and citation indexes in 1960, policy-makers and managers have preferred to use the numbers (publications and citations) to evaluate research/er performances since ease of use. However, disciplinary differences must be considered to evaluate research/ers accurately. Evaluations without considering these differences might end up with misjudgments in tenures and incentives.

The most different field from others is the arts and humanities. The percent of articles is $30 \%$ in A\&HCI, while it is $58 \%$ for SSCI and $70 \%$ for SCIE. On the other hand, $44 \%$ of publications are book reviews for A\&HCI (19\% for SSCI and 33\% for SCIE). The field differs significantly in terms of publications and citation patterns, especially compared to positive sciences. Many studies in the literature reveal the characteristics of the field [1-5]. All these works assert that while co-authorship is common in positive sciences, researchers in the arts and humanities prefer to work alone. The preferred document type for publication is not articles; they produce books, notes, etc. The papers do not get citations as many as the

\footnotetext{
${ }^{*}$ Corresponding author: zehrayanar@gmail.com
} 
other fields. The subjects are mostly local and regional, so the dynamics of international publishing is different from the others. For ex., English papers indexed in A\&HCI is $72 \%$ while it is $94-95 \%$ for SSCI and SCIE. It is possible to extend the list by adding more items because the Arts \& Humanities do not resemble any other filed we know. Therefore, this study aims to reveal the main differences between Arts \& Humanities and the other fields by considering the number of publications and citations, percent of documents cited, percent of highly cited papers, percent of collaboration with industry and internationally, and percent of open access publications. Along with the aim of this study, the research questions addressed are as below:

- To what degree Arts \& Humanities differ from other fields in terms of the number of publications and citations?

- How do Arts \& Humanities differ in words of the number of citations per paper?

- What is the difference between Arts \& Humanities and other fields by percent of documents cited and highly cited

- Do the collaboration practices (percent of industry collaboration and international collaboration) of Arts \& Humanities similar to Social Sciences?

- $\quad$ Are there any differences between Arts \& Humanities and other fields by the percent of open access publications

\section{Methodology}

For evaluating the scientific fields, the main statistics of 59,728,700 papers are gathered from Clarivate Analytics' InCites in terms of the $251 \mathrm{Web}$ of Science subject categories. The publications between 1980 and 2018 are selected for analyzes. To conduct an accurate division between scientific fields, the GIPP mapping table is used ${ }^{1}$. The fields Clinical, PreClinical \& Health and Life Sciences are combined in the title of Health \& Life Sciences. The Engineering \& Technology and Physical Sciences are joined as Pure Sciences \& Engineering. Therefore, the evaluations are conducted for four primary scientific fields: Arts \& Humanities (26 categories), Social Sciences (50 categories), Health \& Life Sciences (92 categories), and Pure Sciences \& Engineering (85 categories). The subject categories of Multidisciplinary Sciences and Linguistics are identified in the two different fields by the GIPP mapping table, so, these two categories are considered in the two different fields as two different entities.

The Kruskal-Wallis test is used to determine whether the four fields differ by the number of papers and citations; citation per publication; percent of documents cited, highly cited papers, industry, and international collaboration and open access publications. In addition to $p$ values, $\eta_{H}^{2}$ formula $\left(\eta_{H}^{2}=(H-k+1) /(n-k)\right.$ where $\mathrm{H}$ is the test value, $\mathrm{k}$ is the number of groups, and $n$ is the total number of observations) is used to calculate the effect size to evaluate the test results more accurately ${ }^{2}$. Calculating $\eta^{2} \geq 0.14$ means a large effect ${ }^{3}$. MannWhitney test is implemented comparing the four fields and to understand the source of difference between fields by the number of papers and citations. The effect size of the MannWhitney test is calculated with Glass (1965) formula, as recommended by Cohen [6]. The formula is $r_{G}=2\left(\bar{R}_{A}-\bar{R}_{B}\right) / N_{T}$, where $\bar{R}_{A}$ and $\bar{R}_{B}$ are average ranks for two groups and $N_{T}$ is the total size. A value above 0.5 may be thought of large effect size.

A boxplot is created for the variable number of citations per paper using $\mathrm{R}$ Commander and KMggplot2 plug-in, which makes it possible to compare the median, minimum and maximum values, range, and quartile range of citations per papers for the fields. It is also

\footnotetext{
${ }^{1} \mathrm{http}: / /$ help.prod-

incites.com/inCites2Live/indicatorsGroup/aboutHandbook/appendix/mappingTable.html

2 http://higheredbcs.wiley.com/legacy/college/cohen/1118436601/pdf/Ch_21.pdf

3 http://imaging.mrc-cbu.cam.ac.uk/statswiki/FAQ/effectSize
} 
possible to examine the distribution of the categories included in each of the four fields through citations per paper. In addition to Kruskal-Wallis test results, median, minimum and maximum values, range, and interquartile range is presented for variables $\%$ of documents cited, percent of documents cited, highly cited papers, industry, and international collaboration and open access publications to show the reasons for differences.

\section{Findings}

Table 1 presents the field-based differences. In terms of the number of publications, the papers published in the fields of Health \& Life Sciences and Pure Sciences \& Engineering are four times more than the Social Sciences and almost eight times than Arts \& Humanities. Disciplinary differences in the publication frequency are quite clear. The median for citations per sub-category is 15 in Health \& Life Sciences, 11 in Pure Sciences \& Engineering, 8 in Social Sciences, and only 0.60 in Arts \& Humanities (see Fig. 1). This finding is essential in terms of showing the citation potential of the Arts \& Humanities. Similarly, the percentage of cited publications in the Arts and Humanities is considerably low. Similar differences are observed for the percent of publications produced with collaboration. The rate of international collaborations is $1 \%$ for Arts and Humanities. On the other side, collaboration with industry is low for all fields, but it is scarcely any for Arts \& Humanities (one in 10,000). Surprisingly, the rate of open access for Arts and Humanities is also lower than other fields.

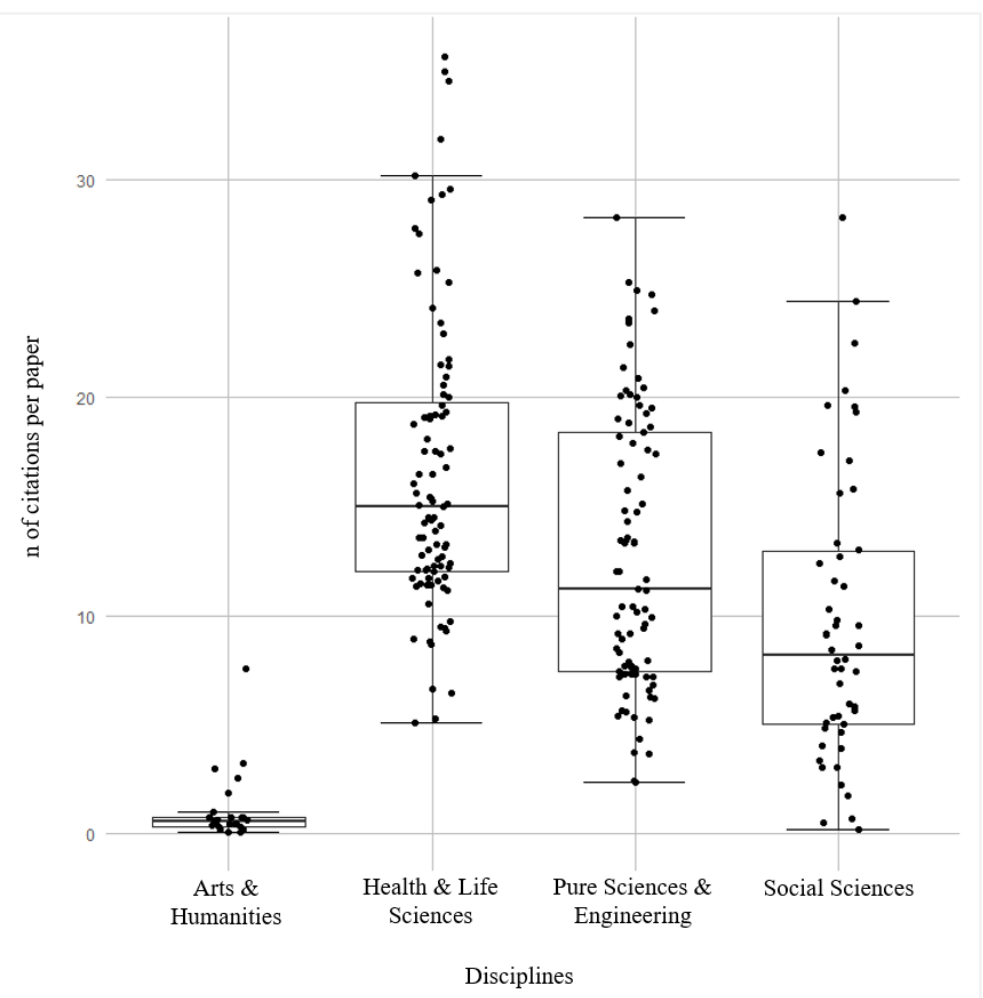

Fig. 1. Distribution of citations per paper for the four fields

When the number of citations per paper is examined more carefully (see Fig 1), disciplinary differences can be seen more clearly. There is a statistically significant difference between four fields predominantly because of Arts \& Humanities as can be easily estimated 
$\left(H=94.002, p<0.001, \eta_{H}^{2}=0.365\right)$. Each dot shown in Figure 1 represents a Web of Science subject category. When the graphic is scrutinized, in addition to need for evaluating Arts \& Humanities separately as a field, the scatter of subject categories refer to the need for evaluating each subject category seperately to understand the patterns more accurately.

Table 1. Descriptives for the scientific production of the fields.

\begin{tabular}{|c|c|c|c|c|}
\hline Descriptives & $\begin{array}{c}\text { Health \& Life } \\
\text { Sciences }\end{array}$ & $\begin{array}{c}\text { Pure Sciences } \\
\text { \& Engineering }\end{array}$ & $\begin{array}{c}\text { Social } \\
\text { Sciences }\end{array}$ & $\begin{array}{c}\text { Arts \& } \\
\text { Humanities }\end{array}$ \\
\hline N of publications & $41,129,467$ & $41,479,185$ & $9,146,177$ & $5,406,112$ \\
\hline Times cited & $771,290,132$ & $571,492,968$ & $\begin{array}{c}91,885,10 \\
9\end{array}$ & $5,782,543$ \\
\hline Documents cited (\%) & $69 \%$ & $66 \%$ & $49 \%$ & $18 \%$ \\
\hline Highly cited papers (\%) & $21 \%$ & $23 \%$ & $17 \%$ & $0.50 \%$ \\
\hline Industry collaboration (\%) & $1.27 \%$ & $1.94 \%$ & $0.32 \%$ & $0.01 \%$ \\
\hline International collaboration (\%) & $15 \%$ & $15 \%$ & $8 \%$ & $1 \%$ \\
\hline Open access (\%) & $17.70 \%$ & $8.73 \%$ & $7.63 \%$ & $2.67 \%$ \\
\hline
\end{tabular}

The number of publications $\left(H=35.101, p<0.001, \eta_{H}^{2}=0.129\right)$, and the number of citations $\left(H=92.998, p<0.000, \eta_{H}^{2}=0.361\right)$ differs in terms of the four fields. To reveal the source of this difference, the Mann-Whitney test is used. The results of the Mann-Whitney test are shown in Table 2.

According to Table 2, there is no statistically significant difference between Health \& Life Sciences and Pure Sciences \& Engineering in terms of the number of publications and citations. On the other hand, there is no difference between Arts \& Humanities and Social Sciences in terms of the number of publications, but they differ by the number of citations. There are statistically significant differences between all other fields with large effect sizes.

The Kruskal-Wallis test is also performed for the other four variables in Table 1; percent of documents cited, highly cited papers, industry collaboration, international collaboration, and open access. It was founded that there is a statistically significant difference between fields by all these variables. Table 3 summarizes the results of the tests, and Table 4 presents descriptive statistics to show how fields differ.

Half of the subject categories under Arts \& Humanies have more than $15 \%$ documents cited. This rate is between $50-69 \%$ for other fields. For he subject category with highest percent of the documents cited in Arts \& Humanities, almost half of the papers are cited. The percent of highly cited papers for the 26 subject categories classified under Arts \& Humanities changes between $0.00 \%$ and $0.05 \%$, whereas it is between $0.00 \%$ and $0.84 \%$ for Social Sciences, $0.01 \%-1.31 \%$ for Pure Sciences \& Engineering, and $0.02 \%-0.62 \%$ for Health \& Life Sciences. Range for the middle half of the subject categories in terms of industry collaboration rate is $1.27 \%$ for Health \& Life Sciences and Pure Sciences \& Engineering. It is $0.29 \%$ for Social Sciences and only $0.01 \%$ for Arts \& Humanities. Health \& Life Sciences and Pure Sciences \& Engineering are also similar for the percent of international collaboration. Median= is about $14 \%$ for both, while it is nearly $8 \%$ for Social 
Sciences, and $0.50 \%$ for Arts \& Humanities. The behaviour of other three fields changes when it comes to the percent of open access publications. Differently, half of the subject categories under Social Sciences, and under Pure Sciences \& Engineering have more than 6$7 \%$ open access publication rates. Health \& Life Sciences doubles them, while percent of the open access publications is lower than $1.77 \%$ for half of the subject categories under Arts \& Humanities.

Table 2. Mann-Whitney test results.

\begin{tabular}{|c|c|c|c|c|c|c|}
\hline \multirow{2}{*}{ Categories } & \multicolumn{2}{|c|}{ Number of publications } & \multicolumn{3}{c|}{ Number of citations } \\
\cline { 2 - 7 } & $U$ & $p$ & $r_{G}$ & $U$ & $p$ & $r_{G}$ \\
\hline $\begin{array}{c}\text { Health \& Life Sciences X } \\
\text { Pure Sciences \& Engineering }\end{array}$ & 3689.500 & 0.517 & - & $\begin{array}{c}3552.50 \\
0\end{array}$ & .294 & - \\
\hline $\begin{array}{c}\text { Health \& Life Sciences X } \\
\text { Social Sciences }\end{array}$ & 1315.000 & 0.000 & 0.428 & 896.000 & 0.000 & 0.610 \\
\hline $\begin{array}{c}\text { Health \& Life Sciences X } \\
\text { Arts \& Humanities }\end{array}$ & 704.000 & 0.001 & 0.411 & 47.000 & 0.000 & 0.961 \\
\hline $\begin{array}{c}\text { Pure Sciences \& Engineering X } \\
\text { Social Sciences }\end{array}$ & 999.000 & 0.000 & 0.530 & 956.000 & 0.000 & 0.984 \\
\hline $\begin{array}{c}\text { Pure Sciences \& Engineering X } \\
\text { Arts \& Humanities }\end{array}$ & 574.000 & 0.000 & 0.480 & 63.000 & 0.000 & 0.943 \\
\hline $\begin{array}{c}\text { Social Sciences X } \\
\text { Arts \& Humanities }\end{array}$ & 642.500 & 0.935 & - & 141.500 & 0.000 & 0.782 \\
\hline
\end{tabular}

Table 3. The Kruskal-Wallis test results for other variables.

\begin{tabular}{|c|c|c|c|}
\hline Variables & $H$ & $p$ & $\eta_{H}^{2}$ \\
\hline \% of documents cited & 108.774 & 0.000 & 0.425 \\
\hline Highly cited papers (\%) & 66.673 & 0.000 & 0.256 \\
\hline Industry collaboration (\%) & 151.576 & 0.000 & 0.597 \\
\hline International collaboration (\%) & 111.335 & 0.000 & 0.435 \\
\hline Open access (\%) & 128.053 & 0.000 & 0.502 \\
\hline
\end{tabular}


Table 4. The descriptive statistics for other variables in terms of four different fields.

\begin{tabular}{|c|c|c|c|c|c|c|}
\hline Variables & Field & Median & Min. & Max. & Range & $\begin{array}{l}\text { Interquartile } \\
\text { range }\end{array}$ \\
\hline \multirow{4}{*}{$\begin{array}{c}\% \text { of the documents } \\
\text { cited }\end{array}$} & Health* & 69.28 & 38.76 & 89.69 & 50.93 & 17.24 \\
\hline & Pure* & 66.11 & 26.77 & 92.89 & 66.12 & 24.40 \\
\hline & Social* & 49.71 & 10.22 & 79.07 & 68.84 & 18.53 \\
\hline & Arts* & 15.20 & 3.04 & 49.95 & 46.91 & 11.47 \\
\hline \multirow{4}{*}{$\begin{array}{l}\text { Highly cited papers } \\
\qquad(\%)\end{array}$} & Health* & 0.19 & 0.02 & 0.62 & 0.60 & 0.22 \\
\hline & Pure* & 0.15 & 0.01 & 1.31 & 1.31 & 0.22 \\
\hline & Social* & 0.13 & 0.00 & 0.84 & 0.84 & 0.21 \\
\hline & Arts* & 0.00 & 0.00 & 0.05 & 0.05 & 0.00 \\
\hline \multirow{4}{*}{$\begin{array}{l}\text { Industry collaboration } \\
(\%)\end{array}$} & Health* & 1.00 & 0.21 & 3.94 & 3.73 & 1.27 \\
\hline & Pure* & 1.94 & 0.28 & 4.87 & 4.59 & 1.27 \\
\hline & Social* & 0.14 & 0.00 & 4.75 & 4.75 & 0.29 \\
\hline & Arts* & 0.00 & 0.00 & 0.19 & 0.19 & 0.01 \\
\hline \multirow{4}{*}{$\begin{array}{c}\text { International } \\
\text { collaboration (\%) }\end{array}$} & Health* & 14.22 & 3.67 & 37.83 & 34.17 & 5.90 \\
\hline & Pure* & 13.89 & 3.82 & 33.02 & 29.21 & 7.72 \\
\hline & Social* & 7.88 & 0.00 & 17.80 & 17.80 & 6.57 \\
\hline & Arts* & 0.50 & 0.06 & 7.57 & 7.51 & 0.65 \\
\hline \multirow{4}{*}{ Open access (\%) } & Health* & 15.58 & 4.43 & 41.01 & 36.59 & 9.41 \\
\hline & Pure* & 7.08 & 1.81 & 31.61 & 29.80 & 5.70 \\
\hline & Social* & 6.15 & 0.00 & 34.85 & 34.85 & 6.08 \\
\hline & Arts* & 1.77 & 0.20 & 8.36 & 8.16 & 2.78 \\
\hline
\end{tabular}

*Health: Health \& Life Sciences, Pure: Pure Sciences \& Engineering, Social: Social Sciences, Arts: Arts \& Humanities 


\section{Results and discussion}

All the findings of the study support other studies in the literature. Statistically, significant differences are found between Arts \& Humanities and others within the scope of the study. These differences underline the need to evaluate Arts and Humanities separately from the others.

In the world, there are some positive developments in evaluating Arts and Humanities. ENRESSH (European Network for Research Evaluation in the Social Sciences and the Humanities) project (https://enressh.eu/about/), which started in 2016 and will continue until April 2020, works to create a new generation and improved research evaluation systems for social sciences and humanities. In addition to ENRESSH, Leiden Manifesto, which has a vital role in research evaluations, emphasizes the local and national structure of arts, humanities, and social sciences [7]. Thanks to all these studies, the current practices on research evaluations can be enhanced for the scholars working for arts and humanities literature.

\section{References}

1. U. Al, M. Şahiner, Y. Tonta. J. Am. Soc. Inf. Sci. Tech. 57, 1011-1022 (2006)

2. M. J. Bates, D. N. Wilde, S. Siegfried. Libr. Inform. Sci. Res. 17, 5-40 (1995)

3. J. Cullars. Libr. Quart. 62, 325-342 (1992).

4. J. E. Knievel, C. Kellsey. Libr. Quart. 75, 142-168 (2005).

5. V. Lariviere, E. Archambault, Y. Gingras, E. Vignola-Gagne. J. Am. Soc. Inf. Sci. Tech. 57, 997-1004 (2006).

6. G. V. Glass. J. Educ. Meas. 2, 91-95 (1965)

7. D. Hicks, P. Wouters, L. Waltman, S. de Rijcke, I. Rafols. Nature 23, 429-431 (2015). 